\title{
O DEBATE EM TORNO DA NATUREZA DA LINGUAGEM: RETOMANDO O CONTRASTE DAS PERSPECTIVAS DE SAPIR E DE CHOMSKY
}

\section{THE DEBATE AROUND THE NATURE OF LANGUAGE: RECALLING THE CONTRAST BETWEEN CHOMSKY AND SAPIR}

\author{
Morgana Fabiola Cambrussi* \\ Doutora em Linguística/Universidade Federal de Santa Catarina \\ Professora da Universidade Federal da Fronteira Sul \\ E-mail: morganacambrussi@yahoo.com.br \\ Chapecó, Santa Catarina, Brasil
}

Daiana do Amaral Jeremias Mestranda em Estudos Linguísticos/Universidade Federal da Fronteira Sul E-mail: daianaah@hotmail.com Chapecó, Santa Catarina, Brasil

*Endereço: Morgana Fabiola Cambrussi

Universidade Federal da Fronteira Sul, Curso de Letras. Rua Canários da Terra, s/n. Seminário, CEP: 89.813140, Chapecó/SC, Brasil.

Editora-chefe: Dra. Marlene Araújo de Carvalho

Artigo recebido em 23/02/2013. Última versão recebida em 16/03/2013. Aprovado em 17/03/2013.

Avaliado pelo sistema Triple Review: a) Desk Review pela Editora-Chefe; e b) Double Blind Review (avaliação cega por dois avaliadores da área). 


\title{
RESUMO
}

Neste artigo, são debatidas as premissas centrais de duas fortes correntes americanas de investigação linguística, uma de base culturalista e outra de base biológica. O objetivo não é elencar um conjunto de elementos distintivos entre escolas do pensamento linguístico, mas argumentar que existem aproximações possíveis, a partir de um esforço interpretativo das teorias linguísticas e da própria história de constituição da ciência linguística. Então, este texto produz uma reflexão distinta daquela comumente encontrada em manuais de linguística ao apresentar uma visão de continuidade, e não de ruptura, entre perspectivas concorrentes de investigação linguística.

Palavras-chave: correntes do pensamento linguístico; culturalismo; inatismo.

\begin{abstract}
In this article we discussed the central premises of two strong currents of American linguistic research one with a cultural approach and other with a biological approach. The goal is not to list a set of distinctive aspects about language schools but to argue that there are common approaches. This view came from an interpretative work of linguistic theories and the inherent history of linguistic science formation. So this text produces a distinct reflection of that commonly found in textbooks of linguistics because we present a vision of continuity and not rupture between contrary perspectives of linguistic research.
\end{abstract}

Keywords: language schools; culturalism; innateness. 


\section{INTRODUÇÃO}

Desde o reconhecimento da linguística como ciência até os dias atuais, o seu domínio se estendeu sobre tantos aspectos da linguagem humana que, se fizéssemos um balanço dos problemas que a ciência da linguagem aborda, provavelmente assumiria as proporções de uma obra gigantesca e pouco integrada entre alguns de seus capítulos ou se limitaria a uma enumeração de trabalhos, em que apenas um resumo de cada problemática exigiria páginas e páginas e, possivelmente, ainda faltaria o essencial (BENVENISTE, 2005).

Abordaremos, neste artigo, um contraste de perspectivas que engrossa o contrapondo da investigação linguística: as visões americanas do estruturalismo culturalista de Edward Sapir e da abordagem biológica de Noam Chomsky. Nesse exercício de pensar as duas visões da linguagem, costumeiramente apartadas, faremos apontamentos que podem sugerir alguma continuidade na sucessão das escolas de investigação linguística - ponto em que a prática, muito reforçada em manuais de introdução, orienta o destaque para a ruptura e o distanciamento de abordagens.

\section{O CENÁRIO DO DEBATE}

A linguística indianista, como já discutido amplamente, teve espaço central no estruturalismo norte-americano. Sapir dedicou-se principalmente ao estudo e à descrição das línguas indígenas norte-americanas, analisando a forma linguística em contraste com aspetos do ambiente, em especial a cultura, o comportamento, a organização social, a natureza, e elencando padrões intrínsecos da organização interna da língua. Coerente com o pensamento formalista, Sapir via a "[...] linguagem como uma forma autossuficiente que fornece ao pensamento e cultura humanos seus canais expressivos adaptando ambos a ela [...].” (CAMARA, 1975, p.206). Esses canais expressivos, que respondem pela ligação que se faz entre pensamento e linguagem, e a influência da cultura e do meio ambiente no desenvolvimento das línguas naturais dentro da teoria sapiriana da linguagem e do pensamento são pontos-cerne de interesse deste trabalho.

Uma abordagem biológica, diferentemente, ajusta a lupa da investigação da linguagem de acordo com a assunção de que ela se define por ser parte de outra natureza, a natureza humana, e conceitua a linguagem como uma faculdade da mente e inerente ao homem. Assim, o ser humano possuiria uma gramática universal, como dotação da espécie, regida por princípios invariantes, que se aplicam e se podem verificar em todas as línguas, e parâmetros, 
cujos valores binários variam de língua para língua e respondem pelas diferenças entre línguas. Por esse modo de pensar a linguagem, a pergunta central não é como funciona essa língua que está fora dos indivíduos e é por eles utilizada como parte ou como expressão de sua cultura, mas o que a externalização linguística, empiricamente observável, pode nos revelar sobre a língua que está dentro da mente dos indivíduos, que é parte da faculdade humana e que não se pode observar diretamente.

Esse cenário já responde pela postura de confrontação entre as duas abordagens científicas da linguagem e é suficiente para que as dissonâncias possam ser situadas. Um dos pontos elegíveis do debate é a tese proposta por Sapir acerca da determinação do pensamento pela linguagem, afirmação que para Chomsky é infundada, já que o pensamento é outra propriedade da mente e, portanto, independente da linguagem. Outro ponto de divergência elegível reside na afirmação de Sapir acerca da influência do meio ambiente físico e social no processamento da linguagem; Chomsky ignora em sua teorização sobre a competência linguística esses fatores externos, priorizando as capacidades biológicas internas.

\section{O INTERNO E O EXTERNO - A LINGUAGEM E O HOMEM}

Esse intenso enfrentamento filosófico, epistemológico, metodológico constitutivo da ciência linguística não ficou guardado no século passado, pelo contrário, até os dias atuais traz à luz problemáticas pouco clarificadas nas pesquisas linguísticas e enquadramentos (se necessários) difíceis de serem produzidos. Uma divisão, grosso modo, permitiria a classificação dos estudos linguísticos entre aqueles que consideram a linguagem pelo eixo biológico e aqueles que a consideram pelo eixo social ou histórico. Porém, produzir esse tipo de classificação não responde nem à pergunta lugar-comum o que é a linguística, quanto menos poderia nos fazer compreender como ela se organiza.

Pensar pelo eixo biológico já não é prerrogativa gerativista, mas orientação de uma série de trabalhos que, inscritos sob o rótulo de linguística cognitiva ou cognitivista, recobrem da semântica à sintaxe, passando pela pragmática e por aspectos sociais, de funcionamento da linguagem. Pensar pelo eixo social e histórico tampouco restringe as possibilidades de abordagem, já que do culturalismo estruturalista ao assujeitamento discursivo existe a previsão de um componente externo ao homem, quiçá à própria linguagem, socialmente e historicamente construído, que se pode localizar na linguagem, em sua forma opaca. São enquadramentos difíceis de serem produzidos, pois estão sempre sujeitos à contestação. 


\section{Sapir, a linguagem e o pensamento}

Com certeza Sapir foi um dos principais linguistas e antropólogos americanos de seu tempo. É reconhecido como um dos fundadores da etnolinguística, que estuda a relação entre linguagem e cultura, e também como um dos principais acadêmicos envolvidos no desenvolvimento da escola americana de linguística estrutural. Tendo estudado originalmente para se tornar linguista e passando gradualmente para a antropologia, seus interesses eram amplos, incluindo contribuições para a linguística ameríndia, linguística indo-europeia, contribuições antropológicas para a etnologia, teoria da cultura e psicologia cultural.

O livro A linguagem: introdução ao estudo da fala foi uma das maiores contribuições de Sapir para a escola linguística norte americana. Nele, Sapir declarava que alguns cientistas consideravam a língua como um aspecto trivial do nosso cotidiano, isso significava que para nós seres humanos, a língua era uma função tão natural quanto andar, dormir, respirar, entre outros. Contudo, sustentava que a impressão que temos dessa trivialidade não passa de mera ilusão, pois o processo de aquisição da linguagem é algo muito mais complexo que as ações citadas acima. Segundo ele, uma criança em si mesma já carrega um conjunto complexo de fatores, o qual ele próprio denominou de hereditariedade biológica. Isso implicava que a criança fosse tomada como individualmente apta para o desempenho das funções da língua, pois essa característica biológica seria, conforme o autor, inerente ao homem.

No que tange à linguagem Sapir (1954) segue o pressuposto de que ato de falar é algo já predestinado ao homem. Contudo, deve-se considerar que o ser humano é um produto de uma sociedade heterogênea, acarretando como consequência particularidades específicas das tradições das comunidades onde é exposto e criado. Desse modo, falar é uma ação humana que é sensível às variações. Essa variação será determinada pelo grupo social ao qual o indivíduo pertence, sem uma limitação prevista ou possível de predição, visto que é um produto do uso social e herdada historicamente pelas comunidades de fala - essa variação inerente à linguagem é, ao mesmo tempo, alimento e produto da cultura.

Quanto à linguagem, Sapir (1954, p.22) define-a como:

[...] um método puramente humano e não-instintivo de comunicação de ideias, emoções e desejos por meio de um sistema de símbolos voluntariamente produzidos. Entre eles, avultam primacialmente os símbolos auditivos, emitidos pelos chamados "órgão da fala". Não há uma base discernível de instinto na fala humana considerada como tal, embora muitas expressões instintivas e a própria natureza ambiente sirvam de estímulo ao desenvolvimento de certos elementos linguísticos, e embora muitas tendências instintivas, motrizes e outras e outras, ofereçam um teor ou molde predeterminado à expressão linguística. Comunicações, humana ou animais [...] 
decorrentes dos gritos involuntários instintivos não constituem, a nosso ver, fatos de linguagem.

Por essa definição, é possível deduzir que a linguagem em Sapir (1954) não é apresentada como possuidora de uma localização definida na mente-cérebro, biológica ao ponto de estar contida em um órgão, o órgão da linguagem. Pelo contrário, para Sapir, a linguagem é um construto simbólico dos elementos empíricos e fisiológicos. Mas Sapir pressupôs certa localização interna da linguagem, decorrente da própria hereditariedade biológica que acompanha o desenvolvimento da linguagem e que acaba por estruturar outros aspectos pertinentes à atividade humana, como a organização social, intelectual, cultural.

A partir desse pressuposto, Sapir introduz a ligação de dependência entre a linguagem e o pensamento, principalmente no que se refere à possibilidade negativa da existência do pensamento sem a linguagem. Para esse culturalista, a linguagem origina o pensamento. Contudo, o autor também ressalta que nem sempre a linguagem vai indicar a presença do pensamento, pois cada conceito tem como símbolo um elemento linguístico e quando praticamos o ato de fala, essa prática pode ser interpretada como a apresentação de determinadas relações estabelecidas entre esses conceitos. (SAPIR, 1954, p.26). Como exemplo, Sapir cita a palavra "casa", que é um elemento linguístico cujo conceito é apenas uma cápsula de pensamento, que contém milhares de experiências distintas e a capacidade de comportar muitas outras.

Para que a linguagem seja de fato desenvolvida é necessário percorrer um caminho que perpasse uma série de atributos psíquicos, estabelecendo uma jornada do estado mental ao raciocínio. Com isso, podemos definir o pensamento como o nível mais alto do potencial da fala, pois ele é obtido através do caminho psíquico percorrido pela linguagem e também pela plenitude dos elementos do discurso. Indo um pouco mais além, a linguagem pode ser considerada exterior ao pensamento como uma expressão simbólica generalizada (ibidem, p.26).

Embora o autor apresente um trajeto que estabelece ligações de dependência da linguagem para a formação do pensamento, ele acredita que o pensamento é possível sem a linguagem, mas considera que isso não é nada simples (ibidem, p.27). Assim, admitindo essa dificuldade, Sapir corrobora a tese da dependência da linguagem para a projeção do pensamento, partindo do pressuposto de que a linguagem é um instrumento aplicado e o pensamento é uma interpretação desse instrumento, o que torna, para ele, inconcebível o pensamento sem a linguagem - justamente porque um só se origina e se desenvolve pelo 
outro. Sendo assim, se o pensamento é a interpretação do conteúdo linguístico, a matéria do pensamento somente existirá se houver material linguístico.

Para Sapir é uma ilusão pensar que o pensamento é independente da linguagem e essa ilusão é produzida por determinado grupo de fatores:

\begin{abstract}
O mais simples deles é a incapacidade de distinguir entre a evocação das imagens e o pensamento. É incontestável que tão depressa tentamos por uma imagem em relação consciente com outra, sentimo-nos arrastados para um curso silencioso de palavras. Pode ser que o pensamento seja um domínio natural, separado do domínio artificial da fala, mas a fala parece ser a única estrada conhecida que nos conduz a ele [...] Outra fonte ainda mais frequente de impressão ilusória de que a linguagem pode ser posta de lado no ato de pensar, é a incapacidade que geralmente se tem, de compreender que a linguagem não se confunde com o seu simbolismo auditivo [...] O simbolismo auditivo pode ser substituído, ponto por ponto por um simbolismo motor ou visual, ou pode ainda ser substituído por outros tipos, mais sutis e fugidios, de transferência, que já não são fáceis de definir. (SAPIR, 1954, p.28).
\end{abstract}

O surgimento do pensamento se dá pelo uso consensual da linguagem, dessa maneira, ele não segue um caminho independente, sua trajetória é dependente da junção destas duas propriedades: a de pensar e a de se comunicar utilizando material linguístico. A cada símbolo linguístico reproduzimos um conceito mental e sua compreensão e aplicação (uso) no mundo.

Assim sendo, para Sapir, o pensamento nada mais é que o produto do instrumento da faculdade da linguagem, e esta trabalha inconscientemente dentro das propriedades cerebrais, fazendo com que o pensamento desenvolva competências de aperfeiçoamento da linguagem, ou seja, a linguagem cria o pensamento e este aperfeiçoa a linguagem, estabelecendo um processo de interação complexo.

Posterior ao desenvolvimento dessa tese, o contato entre Sapir e Benjamin Lee Whorf no que tange à pesquisa das línguas ameríndias e à relação entre o pensamento e a linguagem acabou por originar a hipótese Sapir-Whorf. Essa hipótese, radicalizando o pensamento de Sapir, defende a ideia de que a linguagem determina completamente o modo como pensamos. Diferentes manifestações de linguagem conduzem a diferenças de pensamento e de experiência: cada língua incorpora uma visão de mundo, de modo que falantes de línguas diferentes chegam a percepções de mundo diferentes.

Whorf corroborou essa tese a partir da pesquisa desenvolvida à época com a comunidade indígena hopi. Analisando as estruturas gramaticais da língua hopi, percebeu-se de que elas não apresentavam codificações para a passagem de tempo e, na inferência verbal e locativa, o tempo desaparecia enquanto o espaço sofria alterações. Com isso, Whorf sustentou uma ideia de autossuficiência para a língua hopi, já que ela seria capaz de codificar e descrever operatória e pragmaticamente todos os fenômenos do universo. A partir dessa 
afirmação, o linguista refutou a possibilidade do pensamento para os hopi conter a noção de percepção do tempo que passa:

\begin{abstract}
Mesmo que seja possível conceber um número ilimitado de geometrias não euclidianas que dão uma descrição do universo, igualmente validas, que não contém os contrastes que nos são familiares de tempo e de espaço. A teoria da relatividade na física moderna é uma descrição da mesma ordem, concebida em termos matemáticos, e a "visão do mundo" Hopi é uma outra, inteiramente diferente, não matemática e linguística. (WHORF, 1969, p.8. Tradução livre.). ${ }^{1}$.
\end{abstract}

Whorf atribuía ao pensamento o status de um ato complexo e essa complexidade só poderia ser explicada através da linguagem, pois são as leis estruturais da linguagem que desmistificam as formas do pensamento humano. Cada indivíduo produziria um ato de linguagem utilizando estruturas gramaticais correspondentes a sistematizações de sua própria língua; essas sistematizações são complexas, mas imperceptíveis, e modelariam o ato do pensamento. Tais características particulares somente seriam evidenciadas quando comparadas a outras línguas, principalmente aquelas que não pertencem à mesma família linguística.

O pensamento humano se manifestaria, então, como uma propriedade das línguas. Cada língua seria dotada de um amplo sistema de estruturas, que a diferencia das outras e que se compõe por um ordenamento cultural de formas e de categorias que permitem ao indivíduo comunicar-se e analisar conscientemente os tipos de relações humanas estabelecidos entre os grupos culturais. (WHORF, 1969, 186-7).

\title{
Léxico, fonética, morfologia e sintaxe: a possível influência do meio ambiente
}

Na coleção de ensaios "Linguística como ciência”, Edward Sapir retoma a questão da cultura e da língua como elementos parcialmente influenciados pelo ambiente. A influência ambiental é somente detectada através de um traço linguístico coletivo de um grupo estabelecido socialmente. Para exemplificar essa possível influência do ambiente na língua, ele apresenta três componentes gramaticais passíveis dessas dimensões: lexical, fonético, morfológico e sintático, a partir dos quais veremos como a língua poderia refletir o quadro físico e social de uma determinada comunidade.

\footnotetext{
${ }^{1}$ No original: "De même qu'il est possible de concevoir um nombre illimité de géométries non euclidiennes qui donnent une descriptions de l'univers, tout aussi valables, qui ne contiennent pas les contrastes qui nous sont familiers de temps et d'espace. La théorie de la relativité dans la physique moderne est une description du même ordre, conçue en termes mathématiques, et la "vision du monde" Hopi en est une autre, entièrement différente, non mathématique et linguistique.” (WHORF, 1969, p.8).
} 
O conteúdo de uma língua, ou léxico, é o ponto no qual Sapir mais evidencia a influência ambiental, pois seria por ele e através dele que podemos compreender e objetivar, em uma dada comunidade, os componentes físicos, as ideias de mundo, os desejos, as problemáticas, as características culturais, entre outros aspectos. Partindo de suas pesquisas com povos indígenas, o autor afirmou que esses povos não poderiam apresentar os mesmos saberes de mundo que uma comunidade europeia, pois sua cultura não atingiu "[...] um grau de complexidade capaz de incluir interesses praticamente universais [...]" (SAPIR, 1969, p.46).

Um dos exemplos apresentados por ele é o léxico da língua da tribo costeira Nutka. Uma vez que a tribo vive da pesca, o seu principal sustento, os falantes de nutka atribuem termos precisos para as diversas espécies de animais marinhos. Em função do interesse desse povo pela precisão da nomenclatura dos animais, ele designou coletivamente distinções correspondentes aos elementos ambientais que o cercam. Orientação contrária também é possível, se determinado elemento ambiental for indiferente à necessidade desse mesmo grupo, menos especificações lhe serão atribuídas. Nessa condição, “[...] não há limites naturais para a variabilidade dos materiais léxicos na medida em que dão expressão a conceitos provenientes do mundo físico [...]. O léxico, ou seja, o assunto de uma língua, destina-se em qualquer época a funcionar como um conjunto de símbolos, referentes ao quadro cultural do grupo." (ibidem, p.51).

Quanto ao sistema fonético, esse componente seria apenas parcialmente influenciado pelo ambiente e, mesmo assim, essa posição poderia ser contestada. Como exemplo e contraexemplo, Sapir apresenta sistemas fonológicos de comunidades distintas. Um grupo que vive em regiões montanhosas no Cáucaso, por exemplo, reproduziria com aspereza o seu sistema fonológico, teoricamente composto por traços de maior rispidez, isso seria ocasionado devido à adversa região em que vivem. Contudo, o povo esquimó, que vive em um ambiente físico ainda mais apropriado para essa mesma influência, devido às rigorosas situações climáticas e ambientais, apresentaria certa suavidade na composição dos traços fonológicos de seu sistema linguístico. Tal comparação induz Sapir a concluir a incerteza e improbabilidade da influência do meio ambiente no que tange ao componente fonológico das línguas, porém, ele não descarta a existência de semelhanças entre determinadas comunidades que apresentam características ambientais análogas (ibidem, 52-53).

A morfologia e a sintaxe, seguindo o mesmo viés, também não apresentariam correlação entre suas formações linguísticas e aspectos do meio ambiente. A morfologia é definida como um assunto constituído de categorias mentais precisas, “[...] de ordem lógica 
ou psicológica, que recebem um tratamento gramatical, e de métodos formais para expressálas [...]"(ibidem, p.55). Sapir reitera que as comunidades vizinhas podem se assemelhar entre elas no que se refere às características morfológicas sem necessariamente apresentar uma influência. Um exemplo disso é o caso de reduplicação nas línguas indígenas, mas neste sentindo o que ocorre seria um “[...] uso generalizado de um recurso formal apenas.” (ibidem, p.55).

Outro ponto a acrescentar é que comunidades linguísticas vizinhas também podem apresentar diferenças morfológicas, mesmo compartilhando fortemente características do ambiente físico e social. Assim como a morfologia, a sintaxe também não apresentaria relação estrita com o ambiente, pois, para a combinação das palavras em unidades maiores, é possível verificar apenas o conteúdo da forma gramatical e como esta opera dentro de seu sistema formal, sem dependências oriundas de aspectos do ambiente físico e social. Corroborando as afirmações acima, Sapir se vê compelido a admitir:

Sentimo-nos, portanto, talvez relutantemente, forçados a admitir que, com exceção do reflexo do ambiente sobre o léxico de uma língua, nada há na língua em si mesma que se prove estar em associação direta com o ambiente. É o caso então de nos surpreendemos de que, sendo assim, vá se encontrar nas várias partes do mundo um tão grande número de sistemas fonéticos e tipos de morfologia linguística tão profundamente distintos." (SAPIR, 1969 p.59).

Com a influência do ambiente no léxico de um grupo linguístico e cultural, a língua estaria parcialmente condicionada à cultura e isso levaria a crer que exista entre elas um paralelismo, pois o conteúdo lexical de uma língua simbolizaria os elementos presentes em uma cultura, determinando visões de mundo diferentes para cada grupo. No entanto, quanto à cultura, os símbolos linguísticos não sofrem tantas modificações durante um período de tempo devido à transitoriedade do aspecto cultural. Isso se vale pelo caráter conservador do sistema gramatical que não permite facilmente reformulações na estrutura formal. Desse modo, seria impossível "[...] estabelecer uma relação causal entre língua e cultura [...] É o que acontece com muitas séries de sequências históricas, que em dado momento causalmente relacionadas, tendem a divergir com o correr do tempo." (ibidem, p.62).

\section{Chomsky, linguagem e mente}

A pesquisa linguística de Noam Chomsky concerne à fala e à estrutura biológica a ela associada: segundo Chomsky, a capacidade da fala está ligada a um tipo de dotação biológica 
inata da espécie. Essa concepção inaugurou e guiou o desenvolvimento de todo o programa de investigação gerativista. Como uma consequência das investigações e do trabalho de Chomsky, na corrente gerativista de investigação, o objeto de estudo da linguística passa a ser a faculdade da linguagem, uma estrutura mental postulada responsável pela aquisição e pelo desenvolvimento da linguagem. O objetivo central da investigação, nessa perspectiva, é estudar o estado inicial dessa faculdade e como reage diante da exposição do falante aos dados linguísticos (HORSTEIN, 1998).

Dentro da teoria chomskyana, a linguagem é considerada como um órgão biológico de incríveis proporções. Segundo Chomsky, existe uma parte de nosso cérebro que seria dedicada à organização e à estruturação do conhecimento linguístico refletido pela competência linguística do falante, essa parte da mente/cérebro também se constitui como uma particularidade da espécie, que desempenha funções específicas (CHOMSKY, 2008). Com esse postulado, surge também a ideia de complexidade do sistema em que atua a mente/cérebro, em que a linguagem, pelo menos na perspectiva gerativa, ocupa um lugar central.

Essa complexidade da mente, para além da sintaxe, pode ser ampliada até o ponto em que se considerem os processos pelos quais há elaboração de configurações de signos de forma quantitativamente rica (CHIERCHIA, 2008), lexicalmente postos em interface com a gramática, pois se representa um sistema de órgãos com partes especializadas para a resolução de problemas especializados e uma estrutura inata complexa, que muito bem pode responder por questões de estrutura lexical, como a organização dos eventos em classes de verbos regularmente estruturadas. Questões como essa poderiam ser empiricamente verificadas, como é o caso de procedimentos em que bebês e crianças, quando expostos a testes, demonstram uma compreensão precoce das categorias básicas do mundo físico e social, dominando muitas informações que nunca formam apresentadas a elas (PINKER, 1998). A linguagem, então, teria assento em um desses órgãos complexos e de sistemas inatos.

Havendo uma faculdade da linguagem, Chomsky a relaciona com uma propriedade elementar e biologicamente isolada, sendo natural e inata aos seres humanos. Desse modo, cada indivíduo da espécie possui naturalmente uma competência para o desenvolvimento de pelo menos uma língua, ou seja, a estruturação da língua é algo que já está dado e não é apreendido, mas definido pelos dados linguísticos a que o falante é exposto. De maneira filosófica, o linguista cita a frase de David Hume, "mão original da natureza", para demonstrar que uma criança, por exemplo, não precisa apreender que existem sentenças de palavras inteiras ao invés de sentenças de meias palavras, pois esse aspecto estrutural está 
assentado em seu potencial de linguagem e todo indivíduo produzirá sentenças complexas com definição de forma e significado (CHOMSKY, 1998).

Para estabelecer uma teoria da proposta inatista da língua, Chomsky postula a existência de uma gramática universal, composta de princípios e parâmetros, em que cada língua (e todas as diferentes línguas) será o resultado do estado inicial de um indivíduo e do curso da experiência que ele perpassa, garantindo-lhe a fixação de parâmetros válidos para a língua que adquire ou adquiriu. Além desses elementos, mais uma dicotomia compõe a teoria inatista: a competência linguística, relacionada ao potencial gerador e ao conhecimento linguístico que todos os falantes têm, e o desempenho linguístico, que varia de falante para falante e está estritamente ligado ao uso e à experiência de linguagem. Ainda, na competência linguística, entra em funcionamento um dispositivo de aquisição da língua que toma a experiência como um input, fornecendo à língua as condições geradoras de output, tudo estruturado e representado internamente na mente/cérebro. "Os dados de entrada e os dados de saída estão ambos sujeitos a exame; podemos estudar o curso da experiência e as propriedades das línguas que são adquiridas." (ibidem, p.19).

Nos anos 50, junto à "revolução cognitiva", a gramática gerativa surge como um importante fator de desenvolvimento das teorias linguísticas de base cognitiva, e a grande contribuição pode ser, com efeito, marcada no deslocamento que se produz, nos estudos linguísticos, ao se considerar as línguas como produto de uma atividade biológica evolutiva natural da espécie e não como produto da cultura e das relações ambientais, sociais e físicas. A perspectiva biologicizante vê:

\begin{abstract}
O comportamento e seus produtos não como o objeto de investigação, mas como dados que podem fornecer evidência sobre os mecanismos internos da mente e os modos como esses mecanismos operam ao executar ações e interpretar a experiência. As propriedades e padrões que eram o foco de atenção na linguística estrutural encontram seu lugar, mas como fenômenos a serem explicados com inúmeros outros, em termos de mecanismos internos que geram expressões. (CHOMSKY, 1998, p.21).
\end{abstract}

A teoria chomskyana busca trazer à luz, de maneira descritiva, explicativa e preditiva, os mecanismos internos que são utilizados no processamento das línguas naturais, integrantes do aparato de linguagem criativo e inerente ao homem. Essa busca teórica e abstrata passa pela realidade do "magnífico" evento operado nos anos iniciais de aquisição da linguagem, em que crianças adquirem e produzem estruturas altamente complexas em curtos espaços de tempo, tendo apenas uma exposição limitada aos dados de sua língua materna. A questão que perpassa o problema, muitas vezes caracterizado pelo argumento da pobreza de estímulo, é 
explicar como os meios finitos são usados de maneira infinita na aquisição e no processamento das línguas naturais. Chomsky, buscando clarificar esse ponto, compara o acidente da aquisição de uma língua com o acidente do crescimento de órgãos do corpo humano, ou seja, “[...] é algo que acontece com a criança e não algo que a criança faz [...]" (ibidem, p.23).

Pinker, simpatizante da teoria gerativa, definia a gramática universal tal como postulada por Chomsky, como um exemplo de sistema combinatório discreto. Para Pinker, essa gramática é composta de um número finito de elementos discretos, ou seja, as palavras, que são combinadas, formam estruturas maiores, neste caso as sentenças, com propriedades distintas das de seus elementos. Nesse sistema combinatório, há recursos para se gerar um número ilimitado de combinações distintas entre si (PINKER, 2004).

Com esse sistema combinatório de dados em funcionamento, uma criança inspeciona naturalmente hipóteses de uma classe limitada de palavras e, a partir dessa inspeção, especifica determinadas relações de compatibilidade entre os dados. A apreensão deste sistema combinatório discreto faz com que a criança conheça e reconheça muitas informações “[...] sobre fenômenos a que nunca esteve exposta e que não são "semelhantes" ou "análogos" em nenhum sentido bem definido àqueles a que esteve exposta." (CHOMSKY, 2009, p. 258). Isso tudo é parte ou resultado do aparelho de linguagem que a configura na mente, onde teria seu espaço de locação, estruturação e projeção.

\section{Gramática universal: fonologia, semântica e sintaxe}

Inicialmente, é necessário assumir o postulado gerativo de que há uma gramática mental disponível para toda espécie humana, abordada na seção anterior, que possui sistemas de representação independentes de qualquer língua particular. Mas na abordagem específica da gramática das línguas particulares, há certa organização parametrizada e observável, em que "A gramática de uma língua é um sistema de regras que determina certo acoplamento de som e significado" (CHOMSKY, 2009 p. 208). Nela existe um componente gerador que é a sintaxe e dois componentes interpretativos que são a fonologia e a semântica. Esses componentes da gramática, entretanto, por mais que sugiram independências para as línguas particulares, seriam fortemente regidos por elementos universais.

A fonologia universal, por exemplo, busca consolidar um alfabeto fonológico universal, amplo e baseado em um sistema de propriedades fonético-fonológicas suficientes para as diferentes línguas e que estejam de acordo com aspectos como ponto e modo de 
articulação, regidos por um sistema de leis naturais ao trato vocal da espécie. Esse alfabeto é responsável pela definição do conjunto dos possíveis traços que são extraídos de uma dada língua, partindo-se da observação dos dados fornecidos pelas línguas particulares, e cuja representação “[...] deve fornecer toda a informação necessária para determinar como o sinal pode ser produzido e deve, ao mesmo tempo, corresponder a um nível refinado de representação perceptiva" (ibidem, p.202-3).

Os elementos primitivos dessa fonologia universal são os símbolos deste alfabeto fonético-fonológico, e neles estão incluídas as características fonológicas distintas e distintivas, como as propriedades de acento, sonorização, frontalidade e posterioridade entre tantos outros traços que, em conjunto, pretendem-se capazes de mapear o componente fonológico da gramática - que, muito provavelmente, é o componente de maior caráter físico, ainda que sejam produzidas, na realidade, abstratizações dos elementos fonológicos. (ibidem, p.203).

Na teoria gerativa, o componente fonológico da gramática tem como papel converter uma estrutura superficial ainda não fonológica em uma estrutura fonológica passível de interpretação. Essa conversão é operada pelo componente fonológico através de uma sequência de regras aplicadas ciclicamente, de modo que sejam sempre reiteradas, possibilitando a regularidade de sua aplicação e atribuição. Apesar da complexidade sugerida para a estrutura fonológica, as regras que a representam seriam simples e independentemente motivadas (ibidem, p.219).

Já o componente semântico, segundo na linha dos componentes de interpretação da gramática, aplicável em um nível profundo da representação, é caracterizado com obscurantismo, já que, para a proposta de investigação gerativista, esse componente não fornece clareza quanto ao seu funcionamento e suas regras de aplicação, uma vez que as relações semânticas, segundo tais pressupostos de investigação linguística, ainda não são transparentes. Indo ainda mais longe, é possível remontar considerações de partem até mesmo da premissa de que a interpretação semântica de uma sentença é determinada por princípios universais que não dependem estritamente de aspectos de gramática estruturáveis no plano da competência linguística, partindo de "[...] conceitos compreendidos no enunciado e na maneira como são relacionados gramaticalmente [...]” (CHOMSKY, 2009 p. 202).

Ainda assim, é necessário ao modelo de gramática prever o nível de representação semântica dentro da projeção postulada. Sobre esse aspecto, para a representação semântica de uma sentença, é demandado paralelismo entre suas partes e a possibilidade de verificar 
aspectos do componente semântico da gramática em uma estrutura profunda, atribuindo a esses aspectos sua devida configuração semântica. Sobre essa questão:

A estrutura profunda é uma parentetização rotulada de elementos "portadores de significado" mínimos. As regras interpretativas aplicam-se ciclicamente, determinando as interpretações semânticas dos constituintes imediatos de X e a relação gramatical representada nessa configuração de $X$ e suas partes. (CHOMSKY, 2009, p. 227).

O componente sintático na gramática gerativa é o que determina o potencial gerador e combinatório da proposta de representação do conhecimento linguístico. Em uma formulação já exaustivamente referida, é pelo componente sintático que se determina como um conjunto finito de regras geradoras se combina para formar estruturas maiores e com infinitas possibilidades geradas. Esse componente central reúne em si as regras, as possibilidades e as impossibilidades de combinação de regras, as quais podem ser aplicadas para fornecer as estruturas profundas, mapeadas sobre as estruturas superficiais.

O componente sintático define certa classe (infinita) de objetos abstratos (P,S), onde $\mathrm{P}$ é uma estrutura profunda e $\mathrm{S}$, uma estrutura superficial. A estrutura profunda contém toda a informação relevante para a interpretação semântica; a estrutura superficial, toda a informação relevante para a interpretação fonética [leia-se fonológica]" (CHOMSKY, 2009, 208. Acréscimos ).

Então, os componentes fonológico, semântico e sintático constituem partes operantes da gramática, mas, na perspectiva gerativa, não integram o mesmo nível de atuação e formação das estruturas linguísticas. A modularização da gramática não opera apenas a compartimentação dessas estruturas, mas também a hierarquização dos elementos de base, instituindo-se entre eles diferenças fundamentais - do que decorre a leitura dessa proposta de investigação como uma teoria sintaticizante da gramática. Nesse caso, não de gramáticas particulares, mas de uma gramática universal prometida como uma reconstrução: (a) do conhecimento inato que os falantes têm, logo, que a todos é comum e regular, além, claro, (b) das "[...] condições que devem ser satisfeitas pelas gramáticas de todas as línguas [...]" (ibidem, p.209), a partir da observação das próprias línguas naturais.

\section{A NATUREZA FORMAL DA LINGUAGEM: UM DEBATE ENTRE SAPIR E CHOMSKY}

Apesar do claro distanciamento teórico entre o pensamento de Sapir e de Chomsky, refletido largamente na composição das correntes teóricas que integram, é válido ressaltar que 
nem só de pontos de divergência e ruptura se faz a relação entre eles. O percurso deste trabalho, até este ponto, reafirmou questões basilares da investigação linguística de cada um desses autores, porém, também deixou margem para a compreensão de que há continuidade histórica.

Embora Sapir acompanhasse o estruturalismo de Bloomfield em sua definição e essência, já fazia surgirem indagações mentalistas, em muito advindas da reflexão do autor a respeito da relação entre linguagem e pensamento - mas não no que diz respeito a aspectos de aquisição de linguagem, como em Chomsky. Um destaque interessante a se fazer é de que Sapir considerava a linguagem como "órgão da fala", e avaliava que esta é uma atividade inerente ao homem e biologicamente predeterminada.

Apesar de natural, Sapir não concebia a linguagem como atividade simples e sim como uma trama extremamente complexa, envolvendo o cérebro, o sistema nervoso e os órgãos de articulação e audição. Assim, a fala seria resultado dos elementos da experiência e da influência do meio e dos elementos internos do corpo humano. Porém, tomando toda a precaução necessária, é preciso afirmar que, para o estruturalista, como era de se esperar, a linguagem não estava totalmente localizada no cérebro, pois isso implicaria a exclusão da visão individual de mundo e dos interesses e atividades do homem, tão necessárias a um culturalista (SAPIR, 1954).

Apesar das ressalvas, uma relação de intersecção entre Sapir e Chomsky se deixa notar. Além do aspecto já destacado, para ambos a língua não tem uma limitação para a sua representação. Porém, Sapir, um defensor do estruturalismo assim como Bloomfield, preocupava-se em observar objetivamente as formas linguísticas, a exemplo do estudo detalhado das línguas indígenas norte-americanas e de seus sistemas fonético, morfológico e sintático. No entanto, Bloomfield adaptou o pensamento de Sapir com o viés totalmente definido pela teoria behaviorista, em que se priorizava a interação do sistema linguístico como um gerador do refinamento e intensificação das respostas humanas (BLOOMFIELD, 1984) e esse fato pode ter sido gerador do rótulo e do pré-entendimento de um Sapir afetado pelo comportamentalismo linguístico.

É perceptível que cada modo de pensar a linguagem vai assumindo uma trajetória diferente, à medida que seu objeto encontra respaldo no ambiente interno ou no ambiente externo ao homem. Mas, às vezes, a leitura de Sapir nos faz pensar que as discussões não eram tão discretas assim. Ainda sobre Sapir, o autor movimentou intensamente o cenário linguístico e continua a movimentar debates, por exemplo, em torno da hipótese do 
determinismo linguístico, ou atualmente conhecida como Hipótese Sapir-Whorf, segundo a qual a linguagem determina o pensamento.

Sobre esse aspecto, Sapir desenvolve uma lógica para a hipótese de determinação impossível de se compreender, conforme a posição de diversos linguistas da atualidade. Segundo a teoria chomskyana, por exemplo, o pensamento é outra faculdade da mente, assim como a linguagem. Assumindo essa dicotomia, é possível afirmar que linguagem e pensamento são distintos entre si, ou seja, são independentes, impossibilitando então a autenticação de uma hipótese determinista.

Outros autores, como Pinker, consideram que a ideia do determinismo linguístico, mesmo em sua versão mais fraca, é um absurdo convencional, pois não há evidências científicas que o comprovem. Como ficariam os seres destituídos de linguagem? Não pensariam? Outro caso que Pinker traz para discussão é o dos bebês que ainda não aprenderam coisa alguma, mas apresentam rastros de pensamento; outro exemplo são os primatas, que são criaturas extremamente inteligentes, contudo não falam, pois não têm capacidade de aprender palavras; e os adultos humanos que afirmam que suas melhores ideias não estão correlacionadas com as palavras e muito menos sofrem intervenções destas (PINKER, 2004).

Muito embora cientistas como Pinker refutem veementemente a hipótese Sapir-Whorf, ela ainda movimenta esses debates e, ao que parece, acabou difundida nas ciências sociais, principalmente na versão mais fraca: a relativista, em que o pensamento não é determinado, mas parcialmente influenciado pela linguagem, que, de certo modo, facilita o pensamento, afetando inclusive a percepção e a memória. Em síntese, embora muitos autores afirmem ou refutem a hipótese determinista, a existência concreta dela, sua formulação, por mais equivocada que possa parecer a alguns, ainda é um caso que gera movimento teórico, portanto, ainda permanece em aberto (STERNBERG, 2010).

Retornando ao pensamento de Sapir, ele expõe o meio ambiente e social como fator de influência no sistema linguístico e trata a questão da cultura como parte intrínseca da língua, já que esta apresentará as características específicas de cada grupo, principalmente no léxico. Esse modo como o fator cultural influencia na constituição da língua de um povo se contrapõe substancialmente à visão de Chomsky apresentada anteriormente, segundo a qual a cultura não é um fator de influência para a língua. Aparentemente, essa influência é algo provindo do interesse do ser humano, ou seja, uma escolha e não algo a ser influenciado. Em uma palestra realizada no Brasil, em 1996, ao responder a uma pergunta da plateia acerca do papel do contexto e da cultura em sua teoria gerativa, Chomsky afirma: 
O contexto e a cultura desempenham o mesmo papel que exerceram no estudo de qualquer outro aspecto da biologia humana [...] Assim, a cultura e o contexto entram na medida em que você tenta construir um entendimento mais completo de como é a vida humana. Essas abordagens não estão em conflito: uma apoia a outra. Se você quiser estudar abelhas, você vai examinar a natureza interna de uma abelha, você vai querer saber que tipo de coisa ela é. Você também vai examinar a organização social das abelhas, os sistemas de comunicação das abelhas[...] $\mathrm{O}$ fato de que as pessoas acreditam que há algum conflito entre estudar a natureza biológica da linguagem e o contexto é um reflexo dessa irracionalidade... Esses estudos se enriquecem reciprocamente. E uma pesquisa séria numa dessas áreas tira conclusões a partir das outras. (CHOMSKY, 1998, p. 61-2)

Desse modo, a estruturação do conhecimento linguístico tem valores e percursos claramente diferentes para Sapir e Chomsky. Na visão biológica, a competência linguística não é apenas o reflexo da relação entre som e significado, mas também dos princípios da estrutura cognitiva que não são propriamente aspectos da linguagem (CHOMSKY, 2008). No entanto, para ambos, segundo seus escritos, a linguagem é natural e inerente ao homem.

Mas daí à afirmação de inatismo da linguagem é dar um salto que, com certeza, não será respaldado por boa parte da investigação linguística. Bloomfield, por exemplo, afirma que a abordagem inatista dependeria de algum fator não físico, que ele formula como mente, espírito ou vontade. Como esses fatores seguem princípios completamente diferentes dos fatores físicos, fundamentais para uma análise comportamentalista, não dependendo de padrões de causação estímulos/resposta do mundo material, são irrelevantes para a descrição do conhecimento linguístico, que só pode ser adequadamente explicado por fatore físicos que apresentem um real reflexo do uso da linguagem (BLOOMFIELD, 1984).

Ainda no escopo dessa discussão, também o recorte gerativista custa caro à teorização sobre a linguagem proposta. Até hoje se produzem críticas quanto ao fato de que a teoria gerativa deixa de lado aspectos da influência do meio que caracterizam o uso real da língua no processo de interação com o mundo (MARTELOTTA; PALOMANES, 2008). Em outras palavras, a língua (e o estudo de descrição de língua) deveria retratar o comportamento do falante em situações reais de comunicação, onde aspectos sociais desempenham papel relevante. Essas considerações sugerem fortemente que ainda não se conseguiu difundir, entre a comunidade linguística, a ideia de separação entre competência linguística e desempenho linguístico e, muito menos, o isolamento de um dos elementos desse par com fins investigativos. O desempenho linguístico de um falante, por exemplo, poderia ser isoladamente investigado, como resultado da competência linguística do falante somada a fatores de ordem não linguística, tais como: convenções sociais, lado emocional do falante no ato da comunicação, crenças, entre outros (PETTER, 2002). Esse estudo, conforme a teoria 
gerativa, não é inviável, pelo contrário, é viável, mas está fora do foco do que se pretende responder com a investigação chomskyana.

Mas nem só de rejeição se cerca esse quadro teórico. Para Pinker, por exemplo, é evidente que a mente possui um órgão da linguagem. Este órgão seria, naturalmente, um mecanismo de cadeias de palavras, estabelecendo um sistema combinatório discreto, justamente por ser capaz de criar um número ilimitado de combinações distintas a partir de um conjunto de elementos finito, ou seja, esse mecanismo de cadeias de palavras pode gerar uma infinidade de conjuntos de frases gramaticais. (PINKER, 2004). Além de reforçar a hipótese inatista, o autor considera que essa estrutura mental de dados e de variáveis abstratas foi uma revolução no âmbito das pesquisas linguísticas e afirma que essa mesma estrutura da gramática deveria ser apresentada desde o início como um princípio de aquisição de uma língua.

Como se pôde ver, Sapir e Chomsky também comungam a notável capacidade de promover debate e movimentação teórica. Com certeza, são dois pesquisadores que fomentaram e ainda fomentam intensas reflexões no cenário da investigação linguística e do campo da linguagem, de maneira mais ampla, considerando-se suas interfaces: com a sociologia, com a psicologia, com a biologia. Outro ponto notável é que esses autores amarram essas interfaces da ciência linguística a uma proposta de relevância para a descrição de aspectos que tangem à natureza formal da linguagem.

\section{CONSIDERAÇÕES FINAIS}

No início deste artigo, apresentamos estudos de investigação linguística que partem da consideração de que a linguagem é uma faculdade natural do homem e sensível às variações dos grupos heterogêneos; em geral, essa não é uma leitura disponível para a produção de Edward Sapir. O linguista e antropólogo é muito mais lembrado pela posição determinista, radicalizada após sua morte, segundo a qual o pensamento é determinado pela linguagem porque somente seria possível estabelecer conceitos através de símbolos, nesse caso, símbolos linguísticos.

À parte à imediata revolta causada pela afirmação de que a determinação do pensamento pela linguagem faz com que falantes de grupos de línguas diferentes tenham visões de mundo diferentes, pois possuem modo de pensar distintos, a hipótese determinista não está tão esquecida como certas correntes de investigação gostariam. Em especial, a corrente gerativista, que postula a independência entre linguagem e pensamento, pode mesmo 
apresentar fortes evidências contrárias à hipótese, mas também pode ser posta em relação contínua com os estudos de Sapir em outros aspectos do trabalho deste autor.

Como premissa, a linguística antropológica e indianista da primeira parte do séc. XX toma as línguas por reflexos da cultura, carregadas de traços próprios de cada comunidade de língua, de cada etnia e de cada ambiente - premissa especialmente verificável no componente lexical das línguas. Agora apenas parte do grupo de pesquisadores estruturalistas foi além do culturalismo e dedicou-se à reflexão sobre a essência ou natureza da linguagem. Sapir, ao considerar que as línguas são inerentes ao homem, naturais e próprias para a espécie, começa a trilhar um caminho paralelo, que vai se aproximar do posterior discurso dominante na pesquisa linguística e que certamente encontra eco até os dias atuais.

Contudo, é preciso mais do que prudência ao produzir certas aproximações, que, antes de mais nada, são produtos de um esforço interpretativo da recente história da ciência linguística. Diferente de Sapir, na teoria chomskyana, o ambiente físico, cultural e social não é elemento central da estruturação do conhecimento linguístico dos falantes. Mas, em ambas as perspectivas, a natureza formal da linguagem emerge no centro da investigação linguística. Além disso, ambos tocaram ou tocam em pontos nevrálgicos para o entendimento da linguagem e da própria natureza humana.

\section{REFERÊNCIAS}

BENVENISTE, Emile. Problemas de linguística geral I. 5 aed. Campinas: Pontes Editores, 2005.

BLOOMFIELD, L. Language. Chicago: University of Chicago, 1984.

CAMARA, J. M. História da Linguística. Petrópolis: Editora Vozes, 1975.

acadêmica, 1965. Introdução às línguas indígenas Brasileiras. Rio de Janeiro: livraria

CHIERCHIA, G. Semântica. Campinas: Unicamp, 2008.

CHOMSKY, N. Linguagem e mente. São Paulo: Unesp, 3ª edição, 2009. Arquitetura da linguagem. Bauru: EDUSC, 2008.

Brasília: UNB, 1998.

Linguagem e mente: pensamentos atuais sobre antigos problemas.

HORSTEIN, N. Noam Chomsky. In: CRAIG, Edward (org.). Routledge Encyclopedia of Philosophy. Londres: Routledge, 1998. 
MARTELOTTA, M.; PALOMARES, R. Linguística Cognitiva. In: MARTELOTTA, M.

(Org.) Manual de linguística. São Paulo: Editora Contexto, 2008. p. 177-191.

PETTER, M. Linguagem, língua, linguística. In: FIORIN, J. (Org.) Introdução à linguística: I. objetos teóricos. São Paulo: Contexto, 2002. p. 05- 25.

PINKER, S. Como a mente funciona. São Paulo: companhia das letras, 1998. O instinto da linguagem. São Paulo: Martins Fontes, 2004.

SAPIR, E. A linguagem: introdução ao estudo da fala. Rio de Janeiro: instituto nacional do livro, 1954.

Linguística como ciência. Rio de Janeiro: Livraria acadêmica, 1969.

STERNBERG, R. Psicologia Cognitiva. São Paulo: Cengage Learning, 2010.

WHORF, B. Linguistique et Anthropologie. Paris : Denoël, 1969. 